\title{
Paclitaxel-induced neuropathy: potential association of MAPT and GSK3B genotypes
}

\author{
Susanna B Park, ${ }^{1,2,6}$, John B Kwok ${ }^{1,3}$, Clement T Loy ${ }^{1,4}$, Michael L Friedlander ${ }^{5,2}$, Cindy S-Y Lin ${ }^{3}$, Arun V Krishnan \\ Craig R Lewis ${ }^{5,2}$ and Matthew C Kiernan ${ }^{6^{*}}$
}

\begin{abstract}
Background: Paclitaxel treatment produces dose-limiting peripheral neurotoxicity, which adversely affects treatment and long-term outcomes. In the present study, the contribution of genetic polymorphisms to paclitaxel-induced neurotoxicity were assessed in 21 patients, focusing on polymorphisms involved in the tau-microtubule pathway, an important target of paclitaxel involved in neurotoxicity development.
\end{abstract}

Methods: Polymorphisms in the microtubule-associated protein tau (MAPT) gene (haplotype 1 and rs242557 polymorphism) and the glycogen synthase kinase-3 $\beta$ (GSK33) gene (rs6438552 polymorphism) were investigated. Neurotoxicity was assessed using neuropathy grading scales, neurophysiological studies and patient questionnaires.

Results: A significant relationship between the GSK-3B rs6438552 polymorphism and paclitaxel-induced neurotoxicity was evident.

Conclusions: Polymorphisms in tau-associated genes may contribute to the development of paclitaxel-induced neurotoxicity, although larger series will be necessary to confirm these findings.

Keywords: Paclitaxel, Neuropathy, Neurotoxicity, MAPT, GSK3 $\beta$

\section{Background}

The major cytotoxic target of paclitaxel is the microtubule system, which provides stability for cellular shape, signaling and mitosis. Paclitaxel binds to the microtubule component $\beta$-tubulin, interfering with microtubule dynamics and leading to microtubule stabilization, mitotic arrest and ultimately apoptosis in chemo-sensitive cancer cells [1].

Microtubules are also critical for axonal function and provide the major transport route for essential organelles to distal nerve endings [2]. Disruption of axonal transport may interrupt energy mechanisms, leading to axonal degeneration and neuropathy. Paclitaxel causes neuropathy as a prominent dose-limiting side effect [3] and induces microtubule aggregation in the peripheral nervous system [4] and interruptions in anterograde axonal transport [5], suggesting that microtubule dysfunction may be important in the development of neuropathy.
The microtubule-associated protein tau gene (MAPT) encodes the protein Tau, involved in tubulin assembly and polymerization [6]. MAPT has two major haplotypes, $\mathrm{H} 1$ and $\mathrm{H} 2$, which affect Tau splicing and expression [7]. The H1 haplotype is associated with increased MAPT transcription and tau expression [6,8]. MAPT expression is also a marker of paclitaxel resistance, with low expression linked to improved treatment response [9]. Tau is phosphorylated by glycogen synthase kinase-3 $\beta$ (GSK3 $\beta$ ), a signaling protein [10], which has also been linked to paclitaxel chemoresistance [11]. In addition, tau concentration may influence paclitaxel binding affinity to microtubules [12] and paclitaxel and tau may compete for the same $\beta$-tubulin binding sites [13].

Given the putative role of microtubule dysfunction in neurotoxicity, we investigated effects of genetic variation in MAPT and GSK3B on neurotoxicity in paclitaxeltreated patients.

\footnotetext{
* Correspondence: matthew.kiernan@sydney.edu.au

${ }^{6}$ Brain and Mind Research Institute, University of Sydney, Sydney, Australia

Full list of author information is available at the end of the article
} 


\section{Methods}

\section{Study design and patients}

Paclitaxel-treated patients were referred by the Department of Medical Oncology, Prince of Wales Hospital. The study was approved by the South Eastern Sydney Area Health Service and University of New South Wales Human Research Ethics Committee. Participants provided written informed consent. Patients were excluded if there was another potential cause for neuropathy such as diabetes, or evidence of neuropathy (based on clinical examination or neurophysiological study) prior to chemotherapy treatment.

\section{Neurological assessment}

Patients were assessed using the National Cancer Institute Common Toxicity Criteria for Adverse Events-neurosensory subscale (NCI). 18 patients underwent more specialized clinical neurological assessment, using the Total Neuropathy Scale-clinical version (TNSc) [14] and encompassing symptoms, pinprick and vibration sensibility, strength and deep tendon reflexes (total score 0-28). Patient neurotoxicity questionnaires (EORTC-CIPN20) were undertaken. Nerve conduction studies were undertaken to assess compound sensory action potential (CSAP) amplitude of the sural and median nerves. Stimulusresponse curves were recorded from the sensory median nerve at the second digit and the current required to produce a CSAP of $90 \%$ maximal amplitude (i90) was determined using the QTracS stimulus delivery program (Institute of Neurology, UCL). i90 at the 4th week of paclitaxel treatment has been identified as predictive of neurological outcome [15].

\section{Genotype analysis}

Lymphocyte-derived patient DNA samples were genotyped for MAPT Haplotype (H1 Haplotype), the single nucleotide polymorphism rs242557 in $M A P T$, and the single nucleotide polymorphism rs6438552 in GSK3B. Genotypes were coded in three strata- e.g. CC, TC and TT GSK3 $\beta$ rs6438552 genotypes were coded as 0,1 and 2 respectively.

\section{Statistical analysis}

Maximum NCI score, final sural nerve conduction amplitude and i90 amplitude at week 4 were selected as markers of neurotoxicity. Linear regression was utilised for continuous variables and Fisher's exact test for categorical variables. The effects of polymorphisms on sural amplitude and i90 were examined by linear regression, with paclitaxel dose as an a priori predictor variable. The effects of polymorphisms on maximal NCI score was examined by Fisher's exact tests. Wilcoxon signed-ranks test was used to compare baseline and final/week4 results for sural and i90 respectively. The two-sided significance level was $\mathrm{P} \leq 0.05$. As an exploratory analysis, no corrections were done for multiple statistical testing, which should be considered when interpreting the results. All analyses were performed using SPSS (version 21, IBM, NY USA).

\section{Results}

\section{Clinical details}

Clinical details of the 21 paclitaxel-treated patients recruited for the pilot study are shown in Table 1 . The majority of patients had breast cancer (95.2\%; Stages 1-3A) and received four cycles of doxorubicin $60 \mathrm{mg} / \mathrm{m}^{2}$ and cyclophosphamide $600 \mathrm{mg} / \mathrm{m}^{2}$ followed by paclitaxel $80 \mathrm{mg} / \mathrm{m}^{2}$ weekly for 12 weeks $(\mathrm{N}=16)$. The remaining patients received paclitaxel at 2 or 3 weekly intervals. $76 \%$ of patients completed paclitaxel treatment as intended, $14 \%$ ceased prematurely due to neurotoxicity, $5 \%$ due to disease progression and $5 \%$ due to other toxicity.

\section{Neuropathy assessment}

Overall, 76\% of patients experienced neuropathic symptoms at any stage, with $56 \%$ having a maximum grade of mild (NCI grade 1), 31\% moderate (NCI grade 2) and $13 \%$ severe (NCI grade 3). Patients underwent clinical and neurophysiological testing at a median of 90 days (range 22 - 378 days) following completion of treatment. Of these, $67 \%$ had reduced or absent ankle reflex, $44 \%$ had deficits in vibration sense and $28 \%$ in pinprick sensibility. Overall, the total neuropathy score was 0-1 in $39 \%, 2-4$ in $50 \%$ and greater than 5 in $11 \%$.

$43 \%$ of patients reported persisting tingling and numbness in the hands and $48 \%$ reported persisting symptoms in the feet. $24 \%$ of patients reported continuing functional problems with fine motor or walking skills. EORTC CIPN20 questionnaire score was significantly correlated to the maximal NCI grade (correlation coefficient $=0.769$; $\mathrm{P} \leq$.005). Sural amplitude was significantly decreased from baseline pre-treatment to completion of treatment (pre

\begin{tabular}{ll} 
Table $\mathbf{1}$ Clinical details & \\
\hline Clinical variables & \\
\hline Age (mean \pm sem; years) & $51.4 \pm 2.1$ \\
$\quad$ Range (years) & $33-68$ \\
$\%$ Female & $95.2 \%$ \\
Cumulative paclitaxel dose $\left(\mathrm{mg} / \mathrm{m}^{2}\right)$ & $965.5 \pm 80$ \\
$\quad$ Range $\left(\mathrm{mg} / \mathrm{m}^{2}\right)$ & $420-2230$ \\
Estrogen and/progesterone receptor positive & $80 \%$ \\
HER-2/neu positive & $40 \%$ \\
Cancer type - breast cancer & $95.2 \%$ \\
Cancer stage & \\
I - IIB & $47.6 \%$ \\
IIIA - IIIB & $47.6 \%$ \\
IV & $4.8 \%$ \\
\hline
\end{tabular}


$20.4 \pm 2.5 \mu \mathrm{V}$; post $14.9 \pm 2.3 \mu \mathrm{V} ; \mathrm{P} \leq 0.05)$. i90 was significantly increased by the 4 th week of treatment $(\mathrm{N}=15$; pre $4.56 \pm 0.29 \mathrm{~mA}$; week $45.54 \pm 0.52 \mathrm{~mA}, \mathrm{P} \leq .01)$, as in previous studies [15].

\section{Polymorphism analysis}

The proportion of GSK3B rs6438552 genotypes was significantly different between patients with no or mild neurotoxicity (Grade 0/1) and those with moderate/severe neurotoxicity ( $>$ Grade 2 ; Fisher's exact test $=6.411$; $\mathrm{P} \leq .05)$, with the $\mathrm{T} / \mathrm{T}$ genotype associated with reduced neurotoxicity severity (Table 2). However, there were no differences in MAPT haplotype or MAPT polymorphism rs242557 compared to neurotoxicity grade (Fisher's exact test $=0.863$; NS; Fisher's exact test $=2.984 ;$ NS). Further, patients with the C/C genotype of the GSK3 $\beta$ rs6438552 polymorphism demonstrated an odds ratio of 2 with a $95 \%$ CI of .899 to 4.452 with respect to the development of moderate/severe neurotoxicity $(\mathrm{P} \leq .05)$. Accordingly, patients with the T/T polymorphic GSK3B alleles did not demonstrate neurotoxicity greater than Grade 1, while patients with the $\mathrm{C} / \mathrm{C}$ genotype developed only moderate or severe (Grade 2/3) neurotoxicity. Linear regression analysis between polymorphisms and sural amplitude or i90 week 4, with a priori covariate cumulative paclitaxel dose, was not significant for either GSK3B rs6438552, MAPT rs242557 or MAPT haplotype.

\section{Discussion}

The present study examined the potential effects of $M A P T$ haplotype, expression levels, and GSK-3 $\beta$ mediated tau phosphorylation on the development of paclitaxel-induced neuropathy in vivo. Clinical, neurophysiological and genomic approaches, combined with patient questionnaires identified that $G S K 3 B$ polymorphisms may influence the severity of paclitaxel-induced neurotoxicity, with the $\mathrm{C} / \mathrm{C}$

Table 2 Analysis of polymorphism status and maximum neurotoxicity grade

\begin{tabular}{lll}
\hline Genotype (N = 21) & $\mathbf{N C l}$ grade $\mathbf{0 / 1}$ & $\mathbf{N C l}$ grade $\mathbf{2 / 3}$ \\
\hline MAPT haplotype & & \\
11 & $67 \%$ & $67 \%$ \\
12 & $25 \%$ & $33 \%$ \\
22 & $8 \%$ & $0 \%$ \\
MAPT rs24255 & & \\
11 & $42 \%$ & $17 \%$ \\
12 & $42 \%$ & $33 \%$ \\
22 & $16 \%$ & $50 \%$ \\
GSK3B rs6438552 & & \\
CC & $0 \%$ & $50 \%$ \\
TC & $75 \%$ & $50 \%$ \\
$\Pi 1$ & $25 \%$ & 0 \\
\hline
\end{tabular}

genotype of the rs6438552 polymorphism associated with greater severity of neurotoxicity. In contrast, there were no identified effects of MAPT haplotype or the rs 242557 polymorphism on neurotoxicity.

A number of genetic polymorphisms have been previously examined with regards to paclitaxel-induced neurotoxicity, including in drug detoxification pathways [16] and DNA repair mechanisms [17]. The most commonly associated candidate polymorphisms have been in the genes $A B C B 1$ and $C Y P 2 C 8$, associated with the drug metabolism and transport pathways [16,18-20]. Further, a two-fold increase in severe neurotoxicity with paclitaxel treatment has been identified in patients with polymorphisms in FANCD2, associated with defective DNA repair in the FA/BRCA pathway [17]. Genome-wide association studies in paclitaxel-treated patients have identified some additional associations, but these remain to be confirmed $[18,21,22]$. Such approaches have indicated that polymorphisms in ephrin type A receptors involved in neural injury and repair may be associated with risk of paclitaxelinduced neurotoxicity [23]. However, genetic contributions to paclitaxel-induced neurotoxicity seem likely to be polygenic, with different genes producing multiplier effects on overall neurotoxicity risk [21,24]. A suite of 4 polymorphisms associated with drug receptors, transcription, apoptosis, and pain perception lead to a cumulative increased neurotoxicity risk of $62 \%$ [24].

A recent study of 1303 patients investigated polymorphisms in 50 genes to address this variability, identifying that polymorphisms in the P-glycoprotein transporter gene $A B C B 1$ and $\beta$-tubulin gene TUBB2A were the most significantly associated with paclitaxel-induced neurotoxicity, suggesting the role of the tubulin pathway in the pathogenesis of paclitaxel-induced neuropathy [18]. Further, $T U B B 2 A$ polymorphisms were identified in a prior study as protective against paclitaxel neurotoxicity, and found to increase transcription [25]. Similarly, $\beta$-tubulin isotype and tau tumour expression are associated with clinical response to paclitaxel $[9,26]$. Accordingly, $\beta$ tubulin/tau pathway may be relevant in determining toxicity risk and response to paclitaxel treatment.

The H1 haplotype and MAPT polymorphism rs242557 increase $M A P T$ transcription [6,27]. Further, the polymorphism rs6438552 in GSK3 $\beta$ has functional splicing consequences, with the $\mathrm{T}$ allele leading to increased transcription of the splice isoform lacking exons 9 and 11 [22]. The absence of these exonic sequences in GSK3B increases the ability to phosphorylate tau, so there is a 3.8 fold increase in tau phosphorylation in the $\mathrm{T} / \mathrm{T}$ variant compared to the $\mathrm{C} / \mathrm{C}$ isoform [28].

The present study identified that the $\mathrm{T}$ allele of the GSK3B polymorphism rs6438552 may be protective against paclitaxel-induced neurotoxicity, with no patients with the homozygous $\mathrm{T}$ allele demonstrating neurotoxicity greater 
than grade 1 . However, there were no identified effects of $M A P T$ haplotype or the polymorphism rs242557. As discussed, the GSK3B rs6438552 T/T polymorphism increases tau phosphorylation [28], which reduces microtubule stability and the proportion of tau associated with microtubules [10]. Further, GSK3 $\beta$ mediated phosphorylation of MAPT may be protective against axonal damage in vivo [29], suggesting a rationale for risk reduction. Transgenic mice models overexpressing MAPT developed anterograde axonal transport deficits and axonopathy in central axons due to excess tau which stabilised microtubules [29]. However, these effects could be 'rescued' by phosphorylation from excess $G S K 3 \beta$, mediated potentially via protection of axonal transport.

While in neurodegenerative disease GSK3 $\beta$-mediated phosphorylation of tau results in neuronal degradation [30], in paclitaxel-induced neurotoxicity, a reduction in microtubule stabilization may be beneficial to axonal integrity. Both tau and paclitaxel produce enhanced stability of microtubules, interfere with axonal transport, and may share a binding site on $\beta$-tubulin [13]. Microtubules are dynamic structures and small changes in microtubule organization have major impacts on function and on axonal transport [2]. While the present study identified that polymorphisms in GSK3B may be associated with paclitaxel-induced neurotoxicity, a limitation relates to sample size. As such, these findings are preliminary and require confirmation in a larger series. However, an advantage was that objective neurophysiological data was obtained to demonstrate neuropathy, while prior studies utilized clinician-based scales.

\section{Conclusions}

While further studies in a larger cohort will be required to confirm these results, polymorphisms in tau-associated genes (GSK-3B rs6438552) may contribute to the development of paclitaxel-induced neurotoxicity. However, it is important that appropriate clinical, patient-focused and objective neurophysiological outcomes are collected. Paclitaxel-induced neurotoxicity remains a prominent complication of treatment, resulting in early treatment discontinuation and impacts on quality of life. The interindividual variability in the onset and severity of paclitaxelinduced neurotoxicity suggests that patient-specific factors such as genetic polymorphisms may be important in identification of at-risk patients.

\section{Competing interests}

The authors declare that they have no competing interests.

\section{Authors' contributions}

SBP undertook data collection, data analysis and drafted the manuscript. JBK and CTL undertook genetic analyses, data analysis and interpretation and edited the manuscript. AVK and CSYL undertook data collection, data interpretation and edited the manuscript. MLF and CRL contributed to study conception and design, data interpretation and edited the manuscript. MCK contributed to study conception and design, data interpretation and edited the manuscript. All authors read and approved the final manuscript.

\section{Acknowledgements}

SBP is a recipient of a RG Menzies Foundation/ National Health and Medical Research Council of Australia (NHMRC) Training Fellowship [\# 1016446]. Support through NHMRC [Program Grant \# 1037746] is also gratefully acknowledged.

\section{Author details}

${ }^{1}$ Neuroscience Research Australia, University of New South Wales, New South Wales, Australia. ${ }^{2}$ Prince of Wales Clinical School, University of New South Wales, New South Wales, Australia. ${ }^{3}$ School of Medical Sciences, University of New South Wales, New South Wales, Australia. ${ }^{4}$ School of Public Health, University of Sydney, Sydney, Australia. ${ }^{5}$ Department of Medical Oncology, Prince of Wales Hospital, New South Wales, Australia. ${ }^{6}$ Brain and Mind Research Institute, University of Sydney, Sydney, Australia.

Received: 24 April 2014 Accepted: 16 December 2014

Published: 22 December 2014

\section{References}

1. Rao S, He L, Chakravarty S, Ojima I, Orr GA, Horwitz SB: Characterization of the Taxol binding site on the microtubule. Identification of $\operatorname{Arg}(282)$ in beta-tubulin as the site of photoincorporation of a 7-benzophenone analogue of Taxol. J Biol Chem 1999, 274:37990-37994.

2. Baas PW, Ahmad FJ: Beyond taxol: microtubule-based treatment of disease and injury of the nervous system. Brain 2013, 136:2937-2951

3. Rowinsky EK, Donehower RC: Paclitaxel (taxol). N Engl J Med 1995, 332:1004-1014.

4. Jimenez-Andrade JM, Peters CM, Mejia NA, Ghilardi JR, Kuskowski MA, Mantyh PW: Sensory neurons and their supporting cells located in the trigeminal, thoracic and lumbar ganglia differentially express markers of injury following intravenous administration of paclitaxel in the rat. Neurosci Lett 2006, 405:62-67.

5. Theiss C, Meller K: Taxol impairs anterograde axonal transport of microinjected horseradish peroxidase in dorsal root ganglia neurons in vitro. Cell Tissue Res 2000, 299:213-224.

6. Myers AJ, Pittman AM, Zhao AS, Rohrer K, Kaleem M, Marlowe L, Lees A, Leung D, McKeith IG, Perry RH, Morris CM, Trojanowski JQ, Clark C, Karlawish J, Arnold S, Forman MS, Van Deerlin V, de Silva R, Hardy J: The MAPT H1c risk haplotype is associated with increased expression of tau and especially of 4 repeat containing transcripts. Neurobiol Dis 2007, 25:561-70.

7. Baker M, Litvan I, Houlden H, Adamson J, Dickson D, Perez-Tur J, Hardy J, Lynch T, Bigio E, Hutton M: Association of an extended haplotype in the tau gene with progressive supranuclear palsy. Human Mol Genet 1999, 8:711-715.

8. Kwok JB, Teber ET, Loy C, Hallupp M, Nicholson G, Mellick GD, Buchanan DD, Silburn PA, Schofield PR: Tau haplotypes regulate transcription and are associated with Parkinson's disease. Ann Neurol 2004, 55:329-334.

9. Rouzier R, Rajan R, Wagner P, Hess KR, Gold DL, Stec J, Ayers M, Ross JS, Zhang P, Buchholz TA, Kuerer H, Green M, Arun B, Hortobagyi GN, Symmans WF, Pusztai L: Microtubule-associated protein tau: a marker of paclitaxel sensitivity in breast cancer. Proc Natl Acad Sci USA 2005, 102:8315-20.

10. Lovestone S, Reynolds CH, Latimer D, Davis DR, Anderton BH, Gallo JM, Hanger D, Mulot S, Marquardt B, Stabel S: Alzheimer's disease-like phosphorylation of the microtubule-associated protein tau by glycogen synthase kinase-3 in transfected mammalian cells. Current Biology 1994, 4:1077-1086.

11. Fu Y, Hu D, Qiu J, Xie X, Ye F, Lu WG: Overexpression of glycogen synthase kinase-3 in ovarian carcinoma cells with acquired paclitaxel resistance. Int J Gynecol Cancer 2011, 21:439-444.

12. Ross $J \mathrm{~L}$, Santangelo CD, Makrides V, Fygenson DK: Tau induces cooperative Taxol binding to microtubules. Proc Natl Acad Sci USA 2004, 101:12910-12915.

13. Kar S, Fan J, Smith MJ, Goedert M, Amos LA: Repeat motifs of tau bind to the insides of microtubules in the absence of taxol. The EMBO journal 2003, 22:70-77.

14. Cavaletti G, Frigeni B, Lanzani F, Piatti M, Rota S, Briani C, Zara G, Plasmati R, Pastorelli F, Caraceni A, Pace A, Manicone M, Lissoni A, Colombo N, Bianchi G, 
Zanna C, Italian NETox Group: The Total Neuropathy Score as an assessment tool for grading the course of chemotherapy-induced peripheral neurotoxicity: comparison with the National Cancer Institute- Common Toxicity Scale. J Peripher Nerv Syst 2007, 12:210-5.

15. Park SB, Lin CS, Krishnan AV, Friedlander ML, Lewis CR, Kiernan MC: Early, progressive, and sustained dysfunction of sensory axons underlies paclitaxel-induced neuropathy. Muscle Nerve 2011, 43:367-374.

16. de Graan AJ, Elens L, Sprowl JA, Sparreboom A, Friberg LE, van der Holt B, de Raaf PJ, de Bruijn P, Engels FK, Eskens FA, Wiemer EA, Verweij J, Mathijssen RH, van Schaik RH: CYP3A4*22 genotype and systemic exposure affect paclitaxel-induced neurotoxicity. Clin Cancer Res 2013, 19:3316-24.

17. Sucheston LE, Zhao H, Yao S, Zirpoli G, Liu S, Barlow WE, Moore HC, Thomas Budd G, Hershman DL, Davis W, Ciupak GL, Stewart JA, Isaacs C, Hobday TJ, Salim M, Hortobagyi GN, Gralow JR, Livingston RB, Albain KS, Hayes DF, Ambrosone CB: Genetic predictors of taxane-induced neurotoxicity in a SWOG phase III intergroup adjuvant breast cancer treatment trials (S0221). Breast Cancer Res Treat 2011, 130:993-1002.

18. Abraham JE, Guo Q, Dorling L, Tyrer J, Ingle S, Hardy R, Vallier AL, Hiller L, Burns R, Jones L, Bowden SJ, Dunn JA, Poole CJ, Caldas C, Pharoah PP, Earl HM: Replication of genetic polymorphisms reported to be associated with taxane-related sensory neuropathy in patients with early breast cancer treated with Paclitaxel. Clin Cancer Res 2014, 20:2466-75.

19. Leskelä S, Jara C, Leandro-García L, Martínez A, García-Donas J, Hernando S, Hurtado A, Vicario JC, Montero-Conde C, Landa I, López-Jiménez E, Cascón A, Milne RL, Robledo M, Rodríguez-Antona C: Polymorphisms in cytochromes P450 2C8 and 3A5 are associated with paclitaxel neurotoxicity. Pharmacogenomics I 2011, 11:121-9.

20. Hertz DL, Motsinger-Reif AA, Drobish A, Winham SJ, McLeod HL, Carey LA, Dees EC: CYP2C8*3 predicts benefit/risk profile in breast cancer patients receiving neoadjuvant paclitaxel. Breast Cancer Res Treat 2012, 134:401-410.

21. Wheeler HE, Gamazon ER, Wing C, Njiaju UO, Njoku C, Baldwin RM, Owzar K, Jiang C, Watson D, Shterev I, Kubo M, Zembutsu H, Winer EP, Hudis CA, Shulman LN, Nakamura Y, Ratain MJ, Kroetz DL, Cancer and Leukemia Group B, Cox NJ, Dolan ME: Integration of cell line and clinical trial genome-wide analyses supports a polygenic architecture of Paclitaxelinduced sensory peripheral neuropathy. Clin Cancer Res 2013, 19:491-9.

22. Baldwin RM, Owzar K, Zembutsu H, Chhibber A, Kubo M, Jiang C, Watson D, Eclov RJ, Mefford J, McLeod HL, Friedman PN, Hudis CA, Winer EP, Jorgenson EM, Witte JS, Shulman LN, Nakamura Y, Ratain MJ, Kroetz DL: A genome-wide association study identifies novel loci for paclitaxelinduced sensory peripheral neuropathy in CALGB 40101. Clin Cancer Res 2012, 18:5099-109.

23. Leandro-García L, Inglada-Pérez L, Pita G, Hierpe E, Leskelä S, Jara C, Mielgo X, González-Neira A, Robledo M, Avall-Lundqvist E, Gréen H, RodríguezAntona C: Genome-wide association study identifies ephrin type A receptors implicated in paclitaxel induced peripheral sensory neuropathy. J Med Genet 2013, 50:599-605.

24. McWhinney-Glass S, Winham SJ, Hertz DL, Yen Revollo J, Paul J, He Y, Brown R, Motsinger-Reif AA, McLeod HL, Scottish Gynaecological Clinical Trials Group: Cumulative genetic risk predicts platinum/taxane-induced neurotoxicity. Clin Cancer Res 2013, 19:5769-76.

25. Leandro-García LJ, Leskelä $\mathrm{S}$, Jara $\mathrm{C}$, Gréen $\mathrm{H}$, Avall-Lundqvist E, Wheeler $\mathrm{HE}$, Dolan ME, Inglada-Perez L, Maliszewska A, de Cubas AA, Comino-Méndez I, Mancikova V, Cascón A, Robledo M, Rodríguez-Antona C: Regulatory polymorphisms in $\beta$-tubulin lla are associated with paclitaxel-induced peripheral neuropathy. Clin Cancer Res 2012, 18:4441-8.

26. Sève $P$, Reiman $T$, Isaac $S$, Trillet-Lenoir $V$, Lafanechere $L$, Sawyer $M$, Dumontet C: Protein abundance of class III beta-tubulin but not Delta2-alpha-tubulin or tau is related to paclitaxel response in carcinomas of unknown primary site. Anticancer Res 2008, 28:1161-1167.

27. Kwok JB, Loy CT, Hamilton G, Lau E, Hallupp M, Williams J, Owen MJ, Broe GA Tang N, Lam L, Powell JF, Lovestone S, Schofield PR: Glycogen synthase kinase-3beta and tau genes interact in Alzheimer's disease. Ann Neurol 2008, 64:446-454

28. Kwok JB, Hallupp M, Loy CT, Chan DK, Woo J, Mellick GD, Buchanan DD, Silburn PA, Halliday GM, Schofield PR: GSK3B polymorphisms alter transcription and splicing in Parkinson's disease. Ann Neurol 2005, 58:829-839
29. Spittaels K, Van den Haute C, Van Dorpe J, Geerts H, Mercken M, Bruynseels K, Lasrado R, Vandezande K, Laenen I, Boon T, Van Lint J, Vandenheede J, Moechars D, Loos R, Van Leuven F: Glycogen synthase kinase-3beta phosphorylates protein tau and rescues the axonopathy in the central nervous system of human four-repeat tau transgenic mice. J Biol Chem 2000, 275:41340-9.

30. Hernandez F, Gomez de Barreda E, Fuster-Matanzo A, Lucas JJ, Avila J: GSK3: a possible link between beta amyloid peptide and tau protein. Exp Neurol 2010, 223:322-325.

doi:10.1186/1471-2407-14-993

Cite this article as: Park et al:: Paclitaxel-induced neuropathy: potential association of MAPT and GSK3B genotypes. BMC Cancer 2014 14:993.

\section{Submit your next manuscript to BioMed Central and take full advantage of:}

- Convenient online submission

- Thorough peer review

- No space constraints or color figure charges

- Immediate publication on acceptance

- Inclusion in PubMed, CAS, Scopus and Google Scholar

- Research which is freely available for redistribution 